\title{
Prediction of Crack for Drilling Process on Alumina Using Neural Network and Taguchi Method
}

\author{
Kingsun Lee \\ Department of Mechanical Engineering, ChienKuo Technology University, Changhua 500, Taiwan \\ Correspondence should be addressed to Kingsun Lee; kingsun@ctu.edu.tw
}

Received 18 September 2014; Accepted 24 November 2014

Academic Editor: Katsuyuki Kida

Copyright (C) 2015 Kingsun Lee. This is an open access article distributed under the Creative Commons Attribution License, which permits unrestricted use, distribution, and reproduction in any medium, provided the original work is properly cited.

\begin{abstract}
This study analyzes a variety of significant drilling conditions on aluminum oxide (with $L_{18}$ orthogonal array) using a diamond drill. The drilling parameters evaluated are spindle speed, feed rate, depth of cut, and diamond abrasive size. An orthogonal array, signal-to-noise $(S / N)$ ratio, and analysis of variance (ANOVA) are employed to analyze the effects of these drilling parameters. The results were confirmed by experiments, which indicated that the selected drilling parameters effectively reduce the crack. The neural network is applied to establish a model based on the relationship between input parameters (spindle speed, feed rate, depth of cut, and diamond abrasive size) and output parameter (cracking area percentage). The neural network can predict individual crack in terms of input parameters, which provides faster and more automated model synthesis. Accurate prediction of crack ensures that poor drilling parameters are not suitable for machining products, avoiding the fabrication of poor-quality products. Confirmation experiments showed that neural network precisely predicted the cracking area percentage in drilling of alumina.
\end{abstract}

\section{Introduction}

Alumina is the more common name of aluminum oxide $\left(\mathrm{Al}_{2} \mathrm{O}_{3}\right)$ and combination of hardness, high temperature operation, and good electrical insulation makes it useful for a wide range of applications, that is, semiconductor, electronics, and medical and automotive applications. Ceramic drilling is usually achieved by laser, but the use of laser drilling often creates splashes, recast layers, and a tapered bore [1].

Grinding is the most common abrasive process. It is a material removal process accomplished by the application of a bonded grinding wheel-comprised of abrasive particles that are contained in a bonded grinding wheel-applied to a work piece surface while rotating at very high speeds. The typical ceramic is characterized by high hardness and low toughness, along with lack of plasticity and ductility. Following contact with abrasive particles, cracks will be produced in the ceramic. The cutter shape, depth of cut, material property, cutting speed, and abrasive particle are the key points of the grinding process [2].

Funkenbusch et al. [3] used a diamond wheel to grind single crystal alumina (sapphire). They found that increased frequency of use of a diamond grinding wheel resulted in larger grinding force, but grinding efficiency was reduced. Finer abrasive particles resulted in good surface roughness, but the better grinding efficiency of a diamond grinding wheel will reduce surface roughness.

Li et al. [4] used the diamond tool grinding to get the material removed efficiently, the diamond should be tightly integrated on the substrate, and metal bonded wheels are measured at higher bonding strength than resin bonded wheels. The optimal depth of cut can achieve the maximum rate of material removal efficiency, where the cut depth is higher or lower than the optimal depth; however, material removal efficiency will be gradually decreased.

Mohan et al. [5] employed a signal-to-noise ratio to analyze the influence of various parameters on peel-up and push-down delamination factors in drilling of glass fiberreinforced plastic (GFRP). Using Taguchi and response surface methodology, the main objective was to determine the factors that influence delamination and to achieve optimal machining conditions.

Gill and Singh [6] demonstrated the use of an Adaptive Neurofuzzy Inference System technique of fuzzy-based systems to simulate the material removal rate in ultrasonic drilling of alumina ceramic. The performance of the model 
was validated by comparing the predicted results with practical results obtained from corroboration experiments. Davim [7] presented a study of the influence of cutting parameters and cutting time on drilling metal-matrix composites. The objective was to establish a correlation between cutting parameters and evaluators.

Gaitonde et al. [8] presented the methodology of Taguchi optimization method for simultaneous minimization of delamination at drilling entry and exit holes while drilling a melamine coating layered (MDF) panel. It was revealed that the delamination can be effectively reduced in drilling of MDF materials by employing a higher cutting speed and lower feed rate. Janardhan and Krishna [9] applied CNC cylindrical grinding machine with $L_{9}$ orthogonal array to investigate an optimal metal removal rate (MRR) and surface roughness $(\mathrm{Ra})$. The results revealed that feed rate and depth of cut influence predominantly the output responses of metal removal rate (MRR) and surface roughness ( $\mathrm{Ra})$. The results are further confirmed by conducting confirmation experiments.

The optimal control factors for the hole quality were determined by using Taguchi technique [10]. Two cutting tools, cutting speeds, and feed rates were considered as control factors, and $L_{8}$ orthogonal array was determined for experimental trials. Multiple regression analysis was employed to derive the predictive equations of the surface roughness and roundness error achieved via experimental design. Confirmation experiments showed that Taguchi method precisely optimized the drilling parameters in drilling of stainless steel.

Abductive network draws on statistical and multiple regression analysis methods as well as neural networks, resulting in faster and more automated model synthesis. The development of this approach for network learning through self-organization has followed the track of the group method of data handling (GMDH) algorithm and the closely related adaptive learning network (ALN) technique [11]. In this study, abductive modeling technique is able to represent the complex and uncertain relationships between crack and process parameters. It shows that the crack can be predicted with reasonable accuracy based on the developed abductive network.

\section{Taguchi Method and Experimental Design}

Taguchi methods are statistical methods developed by Genichi Taguchi to improve the quality of manufactured products. Robust design method helps ensure customer satisfaction. Robust design focuses on improving the fundamental function of the product or process, thus facilitating flexible designs and concurrent engineering. Indeed, it is the most powerful method available to reduce product cost, improve quality, and simultaneously reduce development interval. Design of experiment (DOE) parameter design techniques are used to determine which controllable factors and which noise factors are the significant variables. The aim is to set the controllable factors at those levels that will result in a product or process being robust with respect to the noise factors $[12,13]$.
TABLE 1: Experimental levels and factors.

\begin{tabular}{lccc}
\hline Factor & \multicolumn{3}{c}{ Levels } \\
& 1 & 2 & 3 \\
\hline$A$, spindle speed (rev/min) & 30000 & 25000 & 20000 \\
$B$, feed rate (mm/min) & 10 & 20 & 30 \\
$C$, depth of cut $(\mathrm{mm})$ & 0.02 & 0.04 & 0.06 \\
$D$, abrasive grain size $(\#)$ & 100 & 140 & 180 \\
\hline
\end{tabular}

TABLE 2: $L_{18}$ orthogonal array.

\begin{tabular}{lllll}
\hline Trial number & $A$ & $B$ & $C$ & $D$ \\
\hline 1 & 1 & 1 & 1 & 1 \\
2 & 1 & 2 & 2 & 2 \\
3 & 1 & 3 & 3 & 3 \\
4 & 2 & 1 & 1 & 2 \\
5 & 2 & 2 & 2 & 3 \\
6 & 2 & 3 & 3 & 1 \\
7 & 3 & 1 & 2 & 1 \\
8 & 3 & 2 & 3 & 2 \\
9 & 3 & 3 & 1 & 3 \\
10 & 1 & 1 & 3 & 3 \\
11 & 1 & 2 & 1 & 1 \\
12 & 1 & 3 & 2 & 2 \\
13 & 2 & 1 & 2 & 3 \\
14 & 2 & 2 & 3 & 1 \\
15 & 2 & 3 & 1 & 2 \\
16 & 3 & 1 & 3 & 2 \\
17 & 3 & 2 & 1 & 3 \\
18 & 3 & 3 & 2 & 1 \\
\hline
\end{tabular}

Taguchi's approach is based on statistical design of experiments, which fulfills the requirements to solve engineering problems and enhance process optimization. The Taguchi method uses a practical design of orthogonal arrays and a relatively small number of experiments to find one set of optimization. This study involved four factors: spindle speed, feed rate, depth of cut, and the grain size of the abrasive diamond. Each factor was used at three levels. Table 1 lists the experimental factors and levels. $L_{18}$ orthogonal array is selected (Table 2) where 18 experiments were carried out to study the effect of drilling parameters. Each experiment was repeated twice in order to reduce experimental errors.

The Taguchi method experiments were used to investigate the relationship between process parameters and crack area in this study. These experiments provide a proper dataset to train the associated abductive network model. Once the abductive network model was constructed, the relationships between input and output variables became available.

\section{Abductive Network Synthesis and Evaluation}

The abductive neural network analysis method has been used for simulation with the aid of a program written in C-language. It has been shown that the prediction accuracy 
in abductive neural networks [14] is much higher than other networks. Abductive neural network analysis based on the abductive modeling technique is able to represent the complex and uncertain relationships between input and output parameters. In an abductive network, a complex system can be decomposed into smaller, simpler subsystems grouped into several layers using polynomial function nodes. The polynomial network proposed by Ivakhnenko [15] is a group of methods of data handling (GMDH) techniques. These nodes evaluate the limited number of inputs by a polynomial function and generate an output to serve as an input to subsequent nodes of the next layer. The general polynomial function in a polynomial functional node can be expressed as follows:

$$
\begin{aligned}
y_{0}= & B_{0}+\sum_{i=1}^{n} B_{i} x_{i}+\sum_{i=1}^{n} \sum_{j=1}^{n} B_{i j} x_{i} x_{j} \\
& +\sum_{i=1}^{n} \sum_{j=1}^{n} \sum_{k=1}^{n} B_{i j k} x_{i} x_{j} x_{k}+\cdots,
\end{aligned}
$$

where $x_{i}, x_{j}, x_{k}$ are the inputs, $y_{0}$ is the output, and $B_{0}, B_{i}, B_{i j}$, $B_{i j k}$ are the coefficients of the polynomial functional nodes.

In this paper, several specific types of polynomial functional nodes were used in a polynomial network to predict the crack of the alumina. These polynomial functional nodes were called normalizer $(N)$, unitizer $(U)$, white node $(W)$, single node $(S)$, double node $(D)$, and triple node $(T)$. These are defined as follows.

(1) Normalizer. A normalizer transforms the original input variables into a relatively common region:

$$
a_{1}=q_{0}+q_{1} x_{1}
$$

where $a_{1}$ is the normalized input, $q_{0}$ and $q_{1}$ are the coefficients of the normalizer, and $x_{1}$ is the original input.

(2) White Node. A white node consists of the linear weight sums of all the outputs of the previous layer:

$$
b_{1}=r_{0}+r_{1} y_{1}+r_{2} y_{2}+r_{3} y_{3}+\cdots+r_{n} y_{n}
$$

where $y_{1}, y_{2}, y_{3}, \ldots, y_{n}$ are the inputs of the node, $b_{1}$ is the output of the node, and $r_{0}, r_{1}, r_{2}, r_{3}, \ldots, r_{n}$ are the coefficients of the white node.

(3) Single, Double, and Triple Node. These are named according to the numbers of the input variables. The algebraic form of each of these nodes is shown in the following equation:

$$
\begin{aligned}
& \text { single: } c_{1}=s_{0}+s_{1} z_{1}+s_{2} z_{1}{ }^{2}+s_{3} z_{1}{ }^{3} \text {, } \\
& \text { double: } d_{1}=t_{0}+\left(t_{1} n_{1}+t_{2} n_{1}^{2}+t_{3} n_{1}^{3}\right) \\
& +\left(t_{4} n_{2}+t_{5} n_{2}{ }^{2}+t_{6} n_{2}{ }^{3}\right)+\left(t_{7} n_{1} n_{2}\right),
\end{aligned}
$$

$$
\text { triple: } \begin{aligned}
e_{1}= & u_{0}+\left(u_{1} o_{1}+u_{2} o_{1}{ }^{2}+u_{3} o_{1}{ }^{3}\right) \\
& +\left(u_{4} o_{2}+u_{5} o_{2}{ }^{2}+u_{6} o_{2}{ }^{3}\right) \\
& +\left(u_{7} o_{3}+u_{8} o_{3}{ }^{2}+u_{9} o_{3}{ }^{3}\right)+u_{10} o_{1} o_{2} \\
& +u_{11} o_{2} o_{3}+u_{12} o_{1} o_{3}+u_{13} o_{1} o_{2} o_{3}
\end{aligned}
$$

where $z_{1}, z_{2}, z_{3}, \ldots, z_{n}, n_{1}, n_{2}, n_{3}, \ldots, n_{n}$, and $o_{1}, o_{2}, o_{3}, \ldots, o_{n}$ are the inputs of the node; $c_{1}, d_{1}$, and $e_{1}$ are the outputs of the node; and $s_{0}, s_{1}, s_{2}, s_{3}, \ldots, s_{n}, t_{0}, t_{1}, t_{2}, t_{3}, \ldots, t_{n}$, and $u_{0}, u_{1}, u_{2}, u_{3}, \ldots, u_{n}$ are the coefficients of the single, double, and triple nodes.

These nodes are third-degree polynomial equations. The double node and triple node have cross-terms, allowing interaction among the node input variables.

(4) Unitizer. A unitizer coverts the output to a real output:

$$
f_{1}=v_{0}+v_{1} i_{1}
$$

where $i_{1}$ is the output of the network, $f_{1}$ is the real output, and $v_{0}$ and $v_{1}$ are the coefficients of the unitizer.

To build a complete abductive network, the first requirement is to train the database. During training, the information given by the input and output parameters must be sufficient. A predicted square error (PSE) criterion is then used to automatically determine an optimal structure. The principle of the PSE criterion is to select the least complex but still accurate network as possible. The PSE is composed of two terms:

$$
\mathrm{PSE}=\mathrm{FSE}+K_{P},
$$

where FSE is the average square error of the network for fitting the training data and $K_{P}$ is the complex penalty of the network, as shown in the following equation:

$$
K_{P}=\operatorname{CPM} \frac{2 \sigma_{p}^{2} K}{N},
$$

where CPM is the complex penalty multiplier, $K$ is the number of coefficients in the network, $N$ is the number of training datasets to be used, and $\sigma_{p}^{2}$ is a prior estimate of the model error variance.

\section{Experiment and Analysis}

A high-speed CNC milling machine was used to drill alumina. Crack areas were measured by tool microscope and crack images were taken by a digital microscope.

The experimental specimens used in this study were alumina $\left(\mathrm{Al}_{2} \mathrm{O}_{3}\right)$ ceramic. The specifications are listed in Table 3. Each specimen, with thickness of $3 \mathrm{~mm}$, was placed on a moveable platform of fixture, as shown in Figure 1.

$4 \mathrm{~mm}$ diameter diamond grinding rods were used in the drilling experiment. The substrate of the diamond grinding rod is SCM440. The diamond particles were electroformed on the grinding rod. 
TABLE 3: Ceramic specifications.

\begin{tabular}{lc}
\hline Item & Specification \\
\hline Material & $99.7 \% \mathrm{Al}_{2} \mathrm{O}_{3}$ \\
Size $\left(\mathrm{mm}^{3}\right)$ & $26 \times 33 \times 3.2$ \\
Hardness $(\mathrm{HV})$ & 1,700 \\
Bending strength $\left(\mathrm{Kgf} / \mathrm{mm}^{2}\right)$ & 3,500 \\
Compression strength $\left(\mathrm{Kgf} / \mathrm{mm}^{2}\right)$ & 30,000 \\
\hline
\end{tabular}

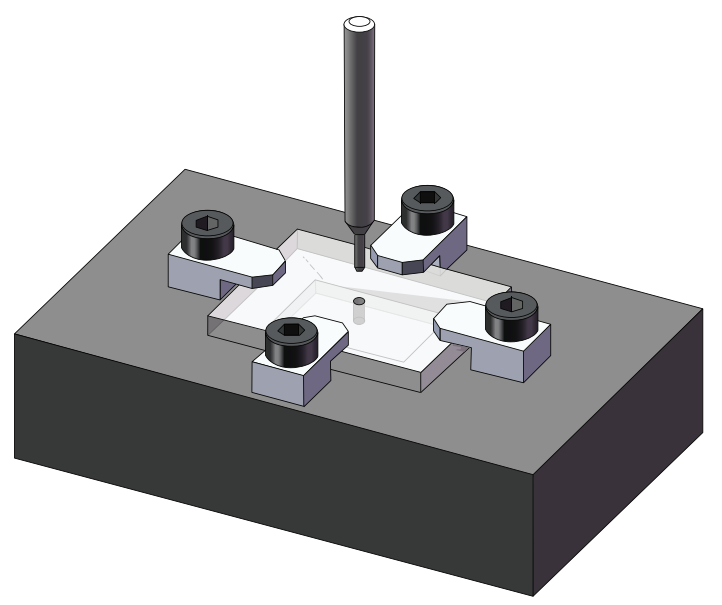

FIgURE 1: Drilling platform.

The crack generated during drilling was measured via microscope. The image was amplified with 150x, and Micro CAM measurement software was applied to evaluate cracking area. The drilling cracking percentage around the holes is determined by the ratio of the crack area $\left(A_{c}\right)$ at the exit side to the ideal whole area $\left(A_{0}\right)$. Figure 2 showed the scheme of crack area after drilling. The value of the cracking percentage $P_{c}$ can be expressed as follows:

$$
\text { Cracking percentage } P_{c}=\frac{A_{c}}{A_{0}}(100 \%) \text {. }
$$

\section{Results and Discussion}

Ceramics offer many advantages compared to other materials. They are harder and stiffer than steel. Small cracking area at the exit side of ceramics denotes better quality. A set of experiments using the Taguchi method were conducted to investigate the relationship between process parameters and cracking percentage. The "smaller the better" quality characteristic for minimum crack should be used to obtain optimal drilling performance. Optimal process design is achieved when the $S / N$ ratio is maximized. Table 4 gives the calculated $S / N$ ratio for the ceramic crack area according to $L_{18}$ orthogonal array. Figure 3 shows the cracking condition of trial number 1 .

The Taguchi method uses $S / N$ ratio to measure the variations of the experimental design. The "smaller the better" quality characteristic was selected for the calculation of $S / N$ ratio since the lowest values of crack were the desired
TABLE 4: Experimental results for cracking percentage.

\begin{tabular}{lccccccc}
\hline $\begin{array}{l}\text { Trial } \\
\text { number }\end{array}$ & $A$ & $B$ & $C$ & $D$ & \multicolumn{2}{c}{ Cracking area percentage (\%) } & S/N ratio \\
\hline 1 & 1 & 1 & 1 & 1 & 11.496 & 11.109 & -21.065 \\
2 & 1 & 2 & 2 & 2 & 17.925 & 18.721 & -25.262 \\
3 & 1 & 3 & 3 & 3 & 102.952 & 104.514 & -40.319 \\
4 & 2 & 1 & 1 & 2 & 16.219 & 15.279 & -23.949 \\
5 & 2 & 2 & 2 & 3 & 18.135 & 16.563 & -24.794 \\
6 & 2 & 3 & 3 & 1 & 41.316 & 39.838 & -32.167 \\
7 & 3 & 1 & 2 & 1 & 14.158 & 14.687 & -23.182 \\
8 & 3 & 2 & 3 & 2 & 38.682 & 37.350 & -31.601 \\
9 & 3 & 3 & 1 & 3 & 25.149 & 24.122 & -27.833 \\
10 & 1 & 1 & 3 & 3 & 88.434 & 84.236 & -38.726 \\
11 & 1 & 2 & 1 & 1 & 7.983 & 8.494 & -18.321 \\
12 & 1 & 3 & 2 & 2 & 33.928 & 32.161 & -30.385 \\
13 & 2 & 1 & 2 & 3 & 25.284 & 22.371 & -27.558 \\
14 & 2 & 2 & 3 & 1 & 9.261 & 10.583 & -19.951 \\
15 & 2 & 3 & 1 & 2 & 15.823 & 17.460 & -24.434 \\
16 & 3 & 1 & 3 & 2 & 39.655 & 43.122 & -32.345 \\
17 & 3 & 2 & 1 & 3 & 19.118 & 20.347 & -25.908 \\
18 & 3 & 3 & 2 & 1 & 30.436 & 28.187 & -29.347 \\
\hline
\end{tabular}

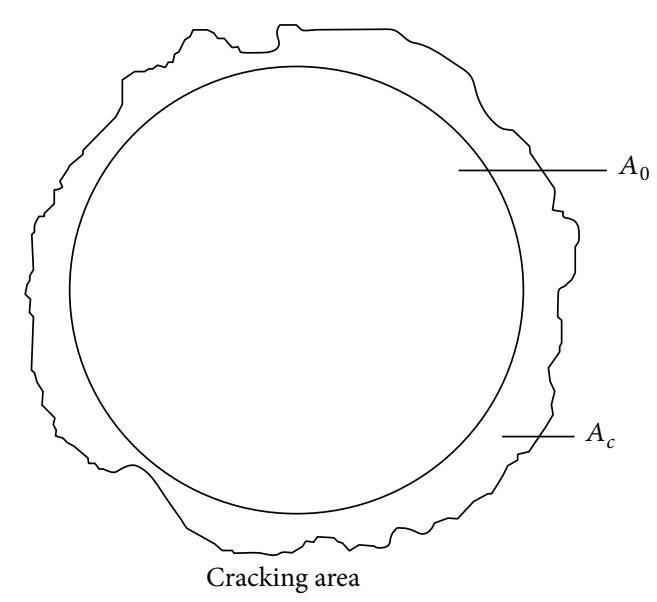

FIGURE 2: Cracking percentage scheme.

result in terms of good product quality. A greater $S / N$ ratio corresponds to a small cracking percentage.

A bigger control factor level difference results in a greater effect on the crack area at the exit side of alumina. The effect of all control factors and level differences can be calculated, as listed in Table 5. $S / N$ ratio response value at level 1 of factor $A$ in Table 5 is the summation of $S / N$ ratio corresponding to factor $A$ at level 1 divided by the number of repetitions of the factor level 1 in Table 4 . Factor $C$ (depth of cut) is the most effective process factor, because it has the highest level of difference among all control factors.

The response diagram is more clearly indicating the effect of each control factor, as shown in Figure 4. Selected factors with higher $S / N$ ratio values will yield minimum 
TABLE 5: $S / N$ ratio response for cracking percentage.

\begin{tabular}{lcccc}
\hline Level & $\begin{array}{c}A \text { (spindle } \\
\text { speed) }\end{array}$ & $B$ (feed rate) & $\begin{array}{c}C \text { (depth of } \\
\text { cut) }\end{array}$ & $\begin{array}{c}D \text { (abrasive } \\
\text { grain) }\end{array}$ \\
\hline 1 & -29.01 & -27.80 & -23.59 & -24.01 \\
2 & -25.48 & -24.31 & -26.75 & -28.00 \\
3 & -28.37 & -30.75 & -32.52 & -30.86 \\
Effect & 3.54 & 6.44 & 8.93 & 6.85 \\
Rank & 4 & 3 & 1 & 2 \\
\hline
\end{tabular}

TABLE 6: ANOVA for cracking percentage.

\begin{tabular}{lccccc}
\hline $\begin{array}{l}\text { Sources of } \\
\text { variance }\end{array}$ & $\begin{array}{c}\text { Degrees of } \\
\text { freedom } \\
\text { (DOF) }\end{array}$ & $\begin{array}{c}\text { Sum of } \\
\text { squares } \\
(\text { SS })\end{array}$ & $\begin{array}{c}\text { Variance } \\
(\text { Var. })\end{array}$ & $F$-ratio & $P$ value \\
\hline$A$ & 2 & 42.602 & 21.301 & 4.12 & 0.054 \\
$B$ & 2 & 124.78 & 62.39 & 12.05 & 0.003 \\
$C$ & 2 & 246.13 & 123.065 & 23.77 & 0 \\
$D$ & 2 & 142.075 & 71.038 & 13.72 & 0.002 \\
Error & 9 & 46.588 & 5.176 & & \\
\hline Total & 17 & 602.175 & & & \\
\hline
\end{tabular}

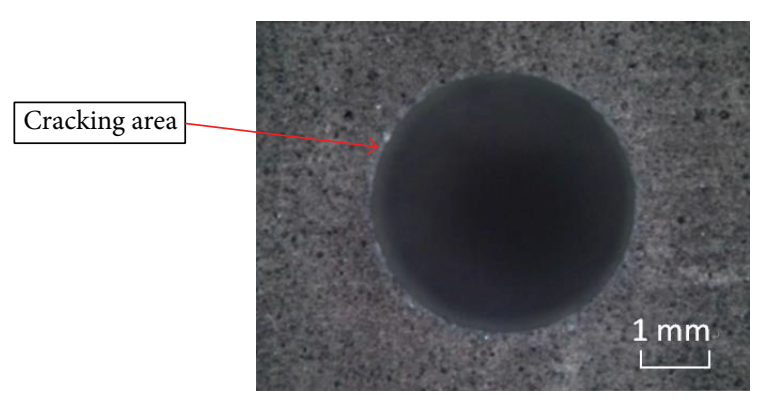

FIGURE 3: Cracking condition of ceramic.

value of crack. It is clear from the figure that the optimum combination of drilling parameters for a minimum crack area is $A 2, B 2, C 1$, and $D 1$ (i.e., spindle speed $=25000 \mathrm{rpm}$; feed rate $=20 \mathrm{~mm} / \mathrm{min}$; depth of cut $=0.02 \mathrm{~mm}$; and abrasive grain $=100$ mesh).

The results of the experiments were evaluated by the analysis of variance (ANOVA). The main objective of the analysis was to determine the influence of every parameter on the variance of the results, regarding the total variance of all the parameters. In this study, ANOVA established the relative significance of factors in terms of $F$-ratio and $P$ value to the response. ANOVA for $S / N$ ratio can be calculated, as shown in Table 6.

The calculation of ANOVA was made on the basis of the equations in [16]. The total sum of the squared deviations SST is decomposed into two components: the sum of the squared deviations SSm due to each factor and the sum of the squared errors SSe.
In ANOVA, total sum of squares (SST) can be calculated as

$$
\mathrm{SST}=\sum_{i=1}^{n} \sum_{j=1}^{r} Y_{i j}^{2}-n * r * \bar{Y}^{2}
$$

where $Y_{i j}$ is the experimental data, $n$ is the number of experiments, each experiment has $r$ experimental data, and $\bar{Y}$ is the grand mean.

The sum of squares (SS) for each factor $m$ can be expressed as

$$
\mathrm{SS}_{m}=\frac{n * r}{L} \sum_{k=1}^{L}\left(\bar{Y}_{k}-\bar{Y}\right)^{2}
$$

where $\bar{Y}_{k}$ is the response values at level $k$ of factor and $L$ is the number of levels:

Total degrees of freedom (DOF)

$=$ Total number of experiments -1 ,

DOF for each factor $=$ Number of levels $(L)-1$,

$$
\begin{aligned}
& \text { Variance }(\text { Var })=\frac{\mathrm{SS}}{\mathrm{DOF}}, \\
& F \text {-ratio }=\frac{\operatorname{Var}}{\text { Var of error }(\mathrm{Ve})}, \\
& P \text { value } \\
& \quad=\text { FDIST }(F \text {-ratio, DOF of factor, DOF of error }),
\end{aligned}
$$

where FDIST is Microsoft Excel function.

From Table 6, it can be observed that speed (Factor $A$ ) is insignificant factor due to $P$ value $>0.05$. The depth of cut (Factor $C$ ) is the most significant drilling factor, indicated by its $P$ value $=0$. The $P$ value was used as a tool to check the significance of each of the factors. The smaller value of $P$ was more significant to the response. The response model is significant at the considered confidence level (95\%) since the response has $P$ value $<0.05$.

To check the accuracy of analysis, a confirmation test needs to be carried out. The estimated $S / N$ ratio for the optimal level of the drilling parameters can be calculated as

$$
\eta_{\mathrm{opt}}=\eta_{\mathrm{avg}}+\sum_{i=1}^{n}\left(\eta_{i}-\eta_{\mathrm{avg}}\right),
$$

where $\eta_{\text {avg }}$ is the mean value of $S / N$ ratio of all control factors, $\eta_{i}$ is the mean $S / N$ ratio at the optimal level $i$, and $n$ is the number of parameters.

Two trials were made in the confirmation test; the results are presented in Table 7. The table shows the comparison of the estimated $S / N$ ratio with the actual $S / N$ ratio using the optimal parameters. It is seen that there is good agreement between the estimated and actual $S / N$ ratios observed. The error is found to be less than 7.501 per cent. Furthermore, the confirmation test verifies that the obtained optimal drilling parameters provide high experimental reliability. 


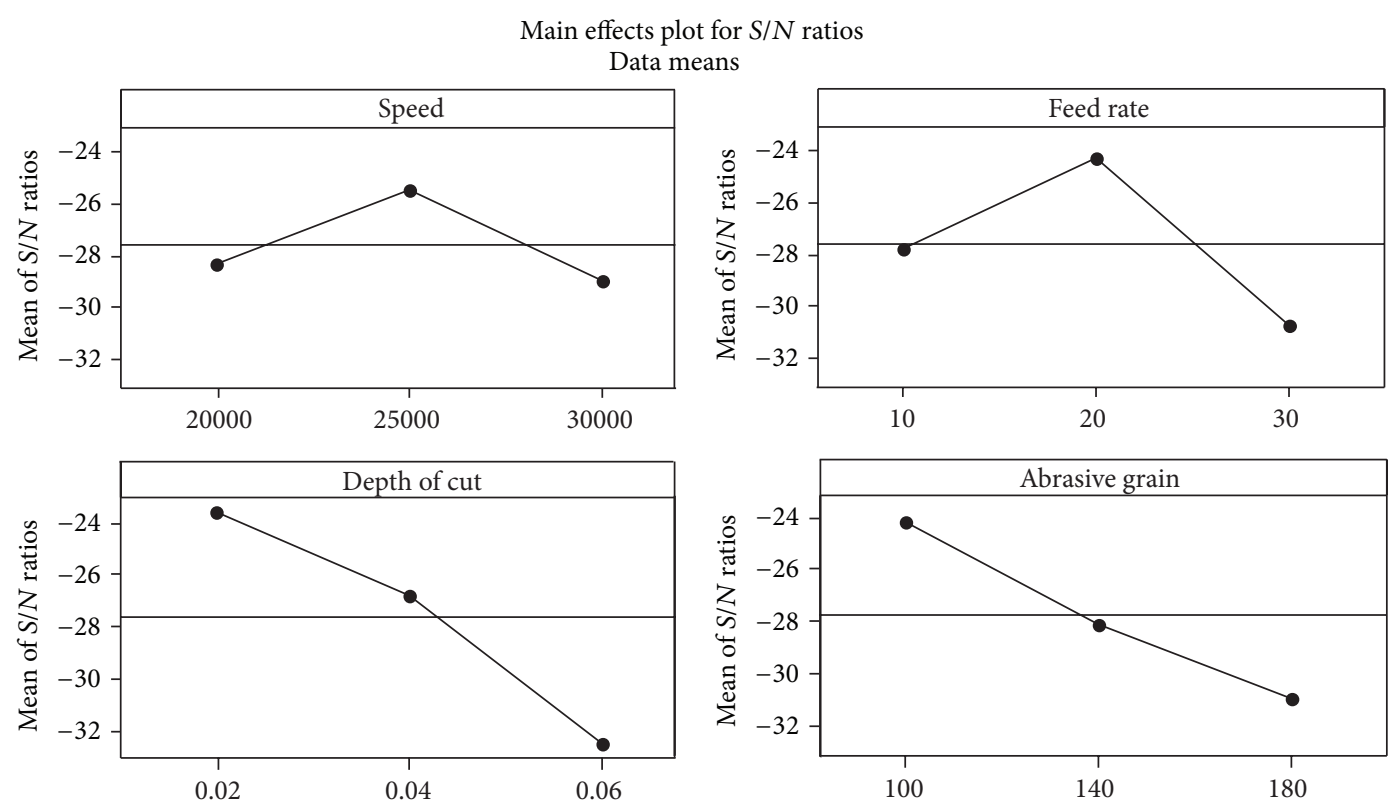

Signal-to-noise: smaller is better

FIGURE 4: Response diagram for cracking percentage.

TABLE 7: Confirmation test results.

\begin{tabular}{lcccc}
\hline $\begin{array}{l}\text { Trial } \\
\text { number percentage }(\%)\end{array}$ & $\begin{array}{c}\text { Cracking } \\
\text { test } S / N \text { ratio }\end{array}$ & $\begin{array}{c}\text { Estimated } \\
\text { value } S / N \text { ratio }\end{array}$ & Error \% \\
\hline 1 & 5.892 & -15.62 & -14.53 & 7.501 \\
2 & 6.183 & & & \\
\hline
\end{tabular}

\section{Prediction of Abductive Network}

The abductive network established the relationship between input parameter and the output parameter during drilling process. To build a complete abductive network, the first requirement is to train the database. Table 4 illustrates the data of process parameters and the cracking percentage of product obtained from the drilling process.

The three-layer abductive networks created were based on the development of the optimal drilling system model. These were comprised of the drilling system parameters and the drilling results synthesized automatically and are capable of predicting the product crack under various drilling modeling techniques.

In the abductive network (appendix), each layer of output had three layers of input (e.g., T2 (Triple2) had T1 (Triple1), T4 (Triple4) and T5 (Triple5) had three layers, T1 had NX2 (NormalizerX2), and NX3 (NormalizerX3) and NX4 (NormalizerX4) had three layers). The input parameters were spindle speed, feed rate, depth of cut, and the grain size of the abrasive diamond. The output result was the cracking percentage. Each node was related to a specific polynomial expression. These polynomial function nodes constituted the complex relationship between the input parameters and the individual output result. If the input parameters are changed, the whole model of this abductive network will change completely. Once the abductive network model was set up, any engineer would have been able to find the cracking area under drilling parameters without any complicated computation required. All polynomial equations used in this network are shown in Figure 5, where

$$
\begin{aligned}
N_{X 1}= & -5.95+0.000238 X 1, \\
N_{X 2}= & -2.38+0.119 X 1, \\
N_{X 3}= & -2.38+59.5 X 1, \\
N_{X 4}= & -4.17+0.0298 X 1, \\
T_{1} & \\
= & -0.903-0.078 N_{X 2}+0.687 N_{X 3}+0.718 N_{X 4} \\
& +0.29 N_{X 2}^{2}+0.443 N_{X 3}^{2}+0.258 N_{X 4}^{2} \\
& +0.0439 N_{X 2} N_{X 3}-0.00296 N_{X 2} N_{X 4} \\
& +0.324 N_{X 3} N_{X 4}+0.115 N_{X 2} N_{X 3} N_{X 4} \\
& +0.219 N_{X 2}^{3}-0.25 N_{X 4}^{3}, \\
T_{4} & -0.87+0.449 N_{X 1}-0.43 N_{X 2}+0.702 N_{X 3} \\
= & +0.296 N_{X 1}^{2}+0.213 N_{X 2}^{2}+0.399 N_{X 3}^{2} \\
& -0.0146 N_{X 1} N_{X 2}+0.441 N_{X 1} N_{X 3} \\
& +0.0167 N_{X 2} N_{X 3}+0.044 N_{X 1} N_{X 2} N_{X 3} \\
& -0.125 N_{X 1}^{3}+0.312 N_{X 2}^{3},
\end{aligned}
$$


TABLE 8: Comparison of cracking percentage between neural network and actual experiment.

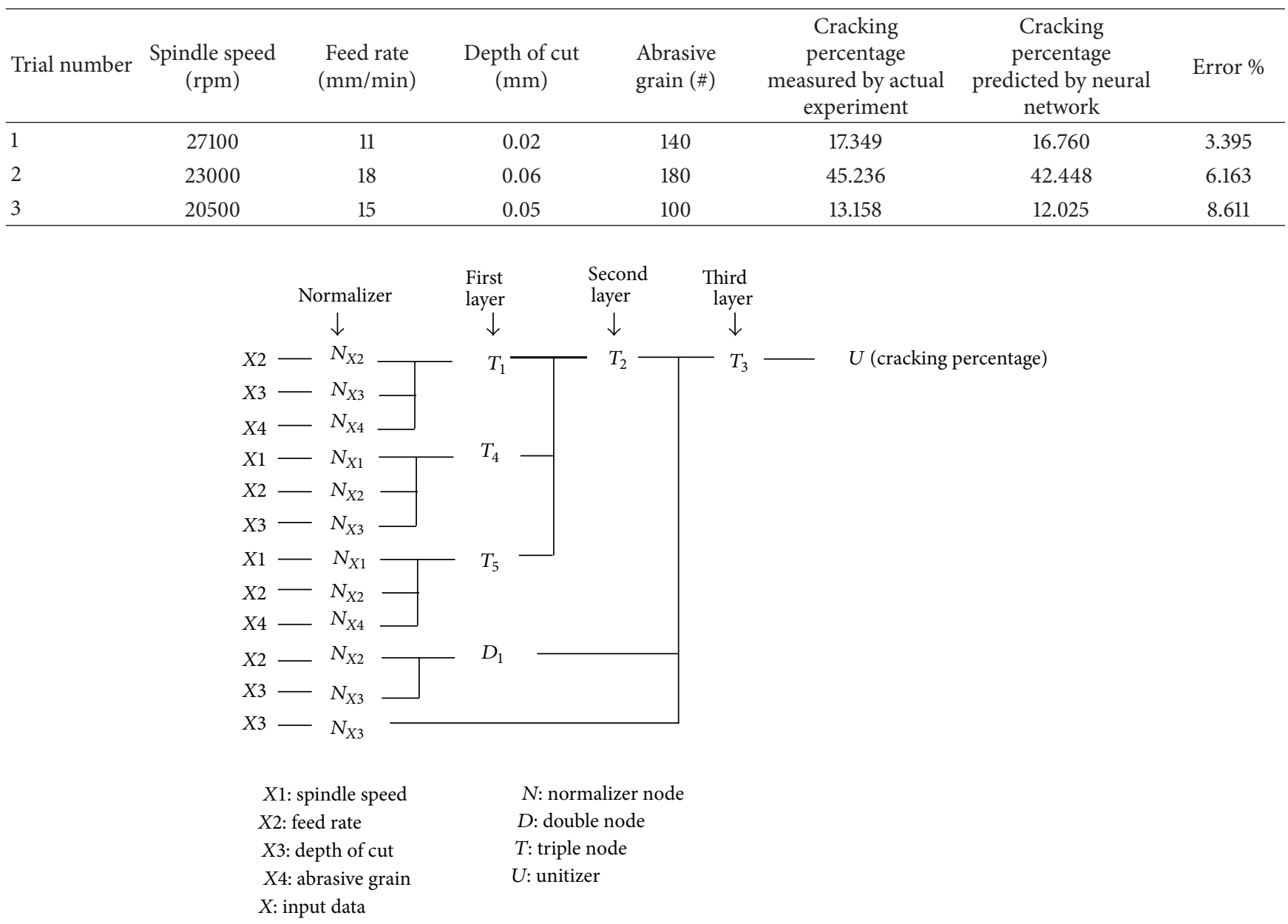

Figure 5

$T_{5}$

$$
\begin{aligned}
= & -0.682+0.342 N_{X 1}+0.0866 N_{X 2}+0.737 N_{X 4} \\
& +0.35 N_{X 1}^{2}+0.0843 N_{X 2}^{2}+0.289 N_{X 4}{ }^{2} \\
& +0.108 N_{X 1} N_{X 2}+0.504 N_{X 1} N_{X 4} \\
& -0.0892 N_{X 2} N_{X 4}+0.0774 N_{X 1} N_{X 2} N_{X 4} \\
& -0.0625 N_{X 1}{ }^{3}+0.0312 N_{X 2}{ }^{3}-0.25 N_{X 4}{ }^{3}
\end{aligned}
$$

$D_{1}$

$$
\begin{aligned}
= & -0.703-0.161 N_{X 2}+0.701 N_{X 3}+0.336 N_{X 2}{ }^{2} \\
& +0.408 N_{X 3}{ }^{2}+0.0187 N_{X 2} N_{X 3}+0.219 N_{X 2}{ }^{3},
\end{aligned}
$$

$T_{2}$

$$
\begin{aligned}
= & -0.284+0.859 T_{1}+0.404 T_{4}-0.407 T_{5} \\
& +0.062 T_{1}^{2}-0.0897 T_{4}^{2}+1.31 T_{5}^{2}-0.271 T_{1} T_{4} \\
& +0.383 T_{1} T_{5}-0.527 T_{4} T_{5}-0.185 T_{1} T_{4} T_{5} \\
& -0.833 T_{1}^{3}-0.288 T_{4}^{3}+2.1 T_{5}^{3},
\end{aligned}
$$

$T_{3}$

$$
\begin{gathered}
=0.00215+0.944 T_{2}+0.0195 D_{1}+0.016 N_{X 3} \\
+0.0477 T_{2}^{2}+0.0845 D_{1}^{2}-0.0514 N_{X 3}^{2} \\
\quad-0.254 T_{2} D_{1}+0.0628 T_{2} N_{X 3}+0.0684 D_{1} N_{X 3} \\
\quad+0.00345 T_{2} D_{1} N_{X 3}+0.0198 T_{2}^{3}-0.0565 D_{1}^{3}, \\
U(\text { cracking percentage })=\text { Output }=32.1+25.3 T_{3} .
\end{gathered}
$$

Table 8 compares the errors predicted by the abductive model with the experimental value. These three experimental cases are excluded from the 18 sets (Table 4 ) of experimental data for establishing the model. This set of data is used to test the appropriateness of the abductive network model. Table 8 shows that the maximum error of cracking percentage is approximately 8.611 per cent, indicating that the proposed abductive model is suitable for drilling process on alumina ceramic. 


\section{Conclusion}

A short hole is defined as a hole with a small ratio of depth to diameter. In this study, a $4 \mathrm{~mm}$ diameter short hole is perforated on $3.2 \mathrm{~mm}$ thickness ceramic, and the crack area obviously appeared when bad drill parameters are selected. This study used the Taguchi method and neural network on alumina $\left(\mathrm{Al}_{2} \mathrm{O}_{3}\right)$ ceramics to optimize drilling conditions with the aim of reducing the crack area at the exit side of alumina. Neural network is used for predicting crack area percentage.

The experimental results may be summarized as follows:

(1) ANOVA verified that factors $C, D$, and $B$ are very significant for drilling alumina. Factor $A$ had less influence.

(2) The optimal combination of drilling parameters was obtained by Taguchi method on alumina ceramic, including spindle speed (factor $A$ ) of $25000 \mathrm{rpm}$, feed rate (factor $B$ ) of $20 \mathrm{~mm} / \mathrm{min}$, depth of cut (factor $C$ ) of $0.02 \mathrm{~mm}$, and abrasive grain size (factor $D$ ) of 100 mesh.

(3) The optimal combination of drilling parameters was confirmed through confirmation experiments. The results indicate that the error between confirmation test and predicted values was within $7.501 \%$.

(4) A comparison was made between the actual drill experiments and the model prediction value of the neural network. The comparison showed that the abductive network model prediction was very close to the actual experimental value, with an error rate of less than $8.611 \%$. The paper demonstrated that engineers can use this abductive model to simulate drilling conditions and predict the crack under any drilling parameters. In addition, the technique can reduce the time needed to experiment.

\section{Conflict of Interests}

The author declares that there is no conflict of interests regarding the publication of this paper.

\section{References}

[1] R. C. Crafer and P. J. Oakley, Laser Processing in Manufacturing, Chapman \& Hall, Hong Kong, 1993.

[2] Z. H. Cai, Ceramic Machining, Quanhua Books, Taipei, Taiwan, 2000.

[3] P. D. Funkenbusch, Y. Zhou, T. Takahashi, and D. Golini, "Grinding of single crystal sapphire: workpiece roughness correlations," Wear, vol. 218, no. 1, pp. 1-7, 1998.

[4] W. Li, Y. Wang, S. Fan, and J. Xu, "Wear of diamond grinding wheels and material removal rate of silicon nitrides under different machining conditions," Materials Letters, vol. 61, pp. 54-58, 2007.

[5] N. S. Mohan, S. M. Kulkarni, and A. Ramachandra, "Delamination analysis in drilling process of glass fiber reinforced plastic (GFRP) composite materials," Journal of Materials Processing Technology, vol. 186, no. 1-3, pp. 265-271, 2007.
[6] S. S. Gill and J. Singh, "Modelling of material removal rate in ultrasonic drilling of alumina ceramic by fuzzy logic," International Journal of Mechatronics and Manufacturing Systems, vol. 2, no. 5-6, pp. 552-565, 2009.

[7] J. P. Davim, "Study of drilling metal-matrix composites based on the Taguchi techniques," Journal of Materials Processing Technology, vol. 132, no. 1-3, pp. 250-254, 2003.

[8] V. N. Gaitonde, S. R. Karnik, and J. Paulo Davim, "Taguchi multiple-performance characteristics optimization in drilling of medium density fibreboard (MDF) to minimize delamination using utility concept," Journal of Materials Processing Technology, vol. 196, no. 1-3, pp. 73-78, 2008.

[9] M. Janardhan and A. G. Krishna, "Determination and optimization of cylindrical grinding process parameters using Taguchi method and regression analysis," International Journal of Engineering Science and Technology, vol. 3, pp. 5659-5665, 2011.

[10] A. Çiçek, T. Kıvak, and G. Samtaş, "Application of Taguchi method for surface roughness and roundness error in drilling of AISI 316 stainless steel," Journal of Mechanical Engineering, vol. 58, no. 3, pp. 165-174, 2012.

[11] A. R. Barron, "Predicted square error: a criterion for automatic model selection, self-organizing methods in modeling," in GMDH Type Algorithms, S. J. Farlow, Ed., Marcel-Dekker, New York, NY, USA, 1984.

[12] S. H. Park, Robust Design and Analysis for Quality Engineering, Chapman \& Hall, London, UK, 1996.

[13] M. S. Phadke, Quality Engineering Using Robust Design, Prentice-Hall, Englewood Cliffs, NJ, USA, 1989.

[14] G. J. Montgomery and K. C. Drake, "Abductive reasoning networks," Neurocomputing, vol. 2, no. 3, pp. 97-104, 1991.

[15] A. G. Ivakhnenko, "Polynomial theory of complex systems," IEEE Transactions on Systems, Man, and Cybernetics, vol. 1, pp. 364-378, 1971.

[16] H. H. Lee, Taguchi Method, Quality Characteristics Concept and Practices, GaoLi Books, Taipei, Taiwan, 2005. 

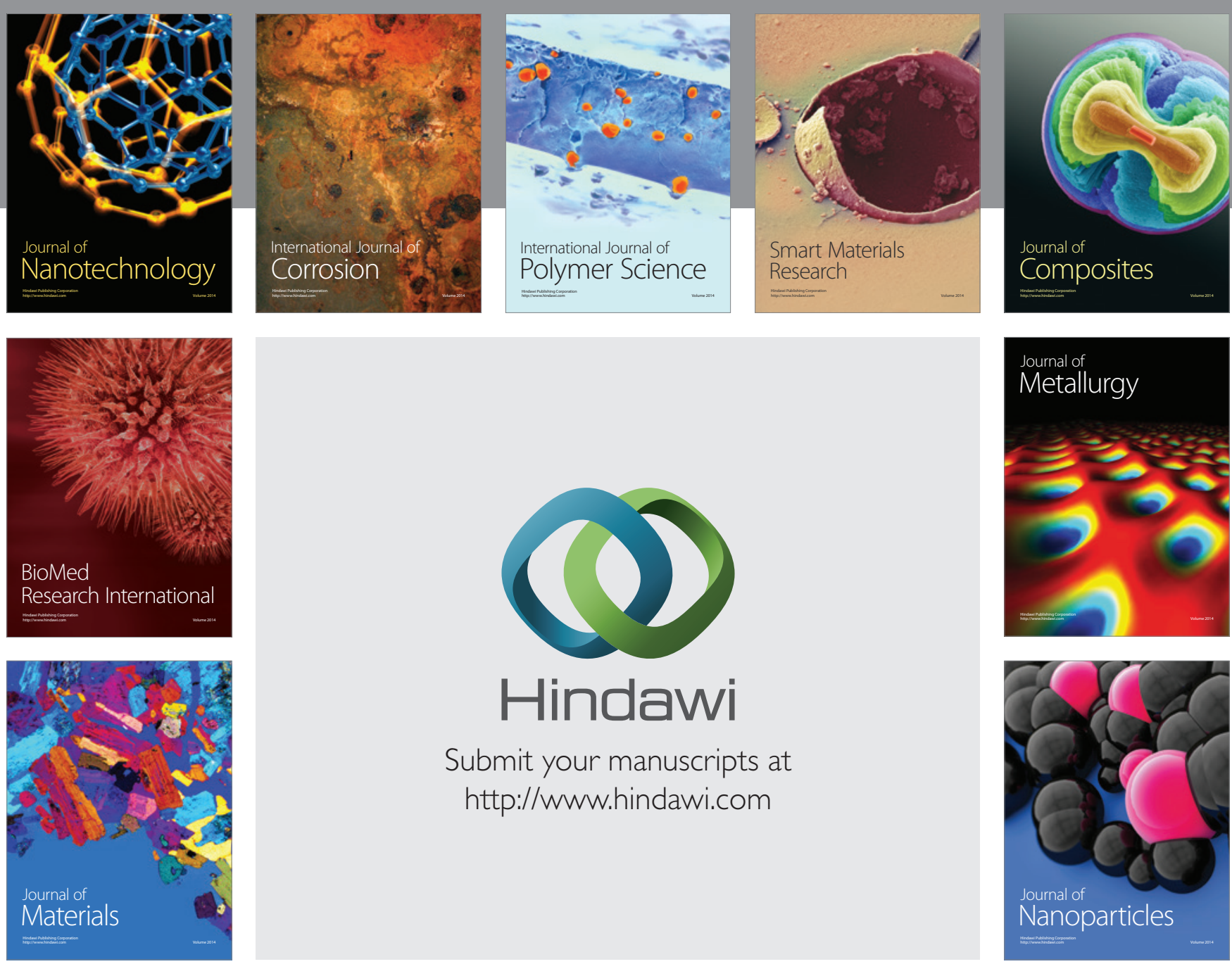

Submit your manuscripts at http://www.hindawi.com
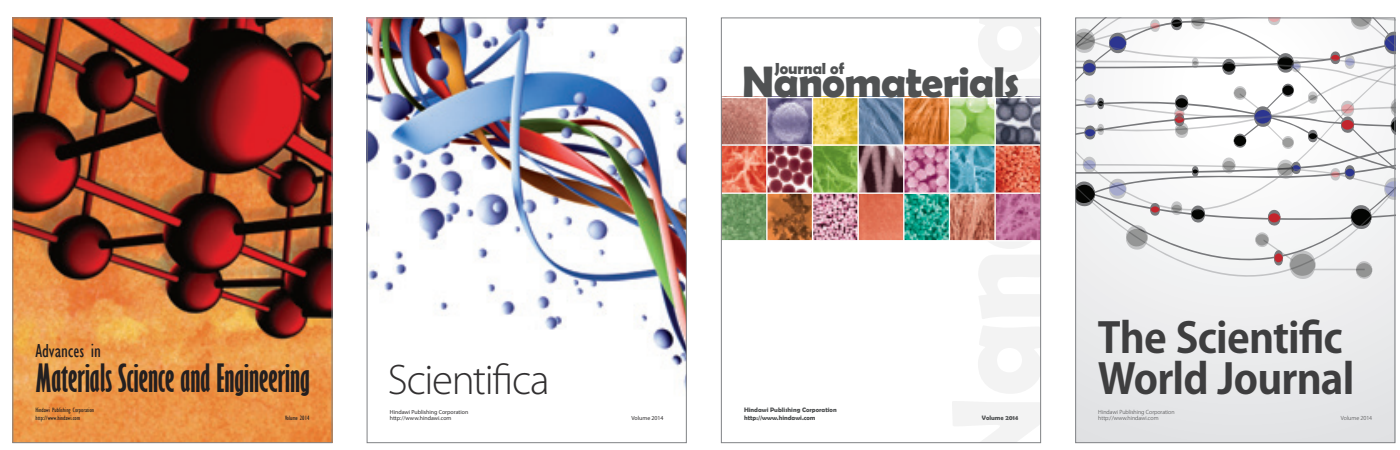

\section{The Scientific World Journal}
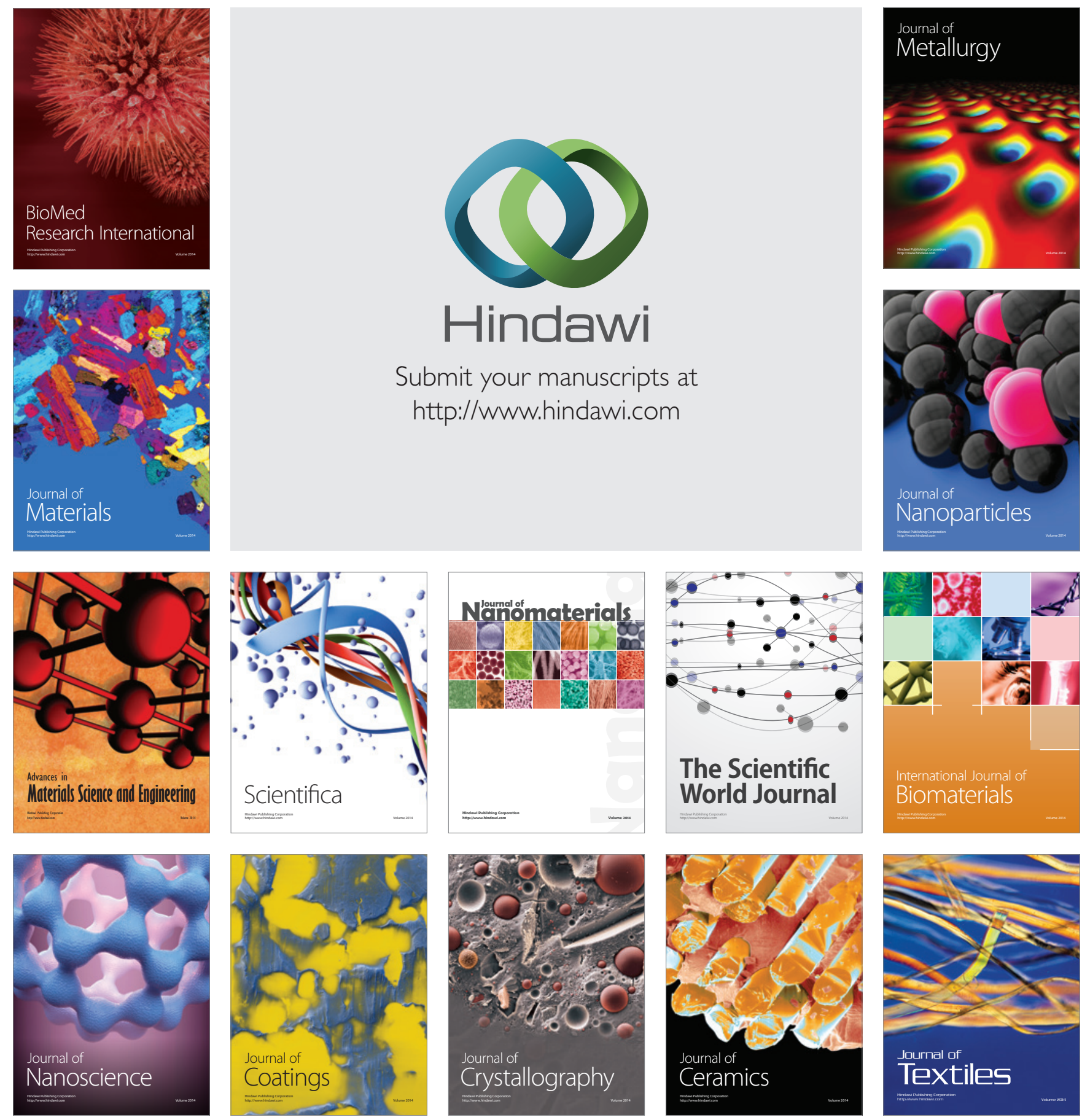